\title{
¿Hacer en el sector público o comprar al sector privado? La regulación de la autoprovisión administrativa en España(*)
}

\section{Make in the public sector or buy from the private sector? The regulation of administrative self-supply in Spain}

\author{
Carlos Alberto Amoedo-Souto ${ }^{(*)}$ \\ Universidad de La Coruña (La Coruña, España)
}

\begin{abstract}
Resumen: El presente trabajo proporciona una panorámica sobre el actual debate de las técnicas de autoprovisión administrativa en España. El concepto de autoprovisión administrativa se utiliza para explicar las distintas opciones a disposición de los gestores públicos para la satisfacción de las necesidades administrativas de bienes y servicios dentro del propio sector público. Se discute también el panorama normativo de las decisiones administrativas de hacer o comprar al mercado, tal y como se configuran por la Ley 9/2017, de contratos del sector público, así como el surgimiento de mercados públicos al margen de los mercados empresariales de compra pública. Finalmente, todo ello se contextualiza en el debate transaccional en curso sobre la necesidad de mejorar la capacidad prestacional del sector público como herramienta de fortalecimiento del Estado de Bienestar.
\end{abstract}

Palabras clave: Autoprovisión administrativa - Decisiones de hacer o comprar al mercado - Ley de Contratos del Sector Público - Derecho Administrativo

\begin{abstract}
This paper draws up an overview on the current status of in-house providing techniques in Spain. The concept of administrative self-supply is provided in order to cover and explain the most common modes of fulfilling the needs of services, goods and utilities whitin the public sector. We discuss the "make or buy decisions", according to the new public procurement Act (9/2017), and the rise of public markets apart from business markets. Finally, we put this subject under the light of the transnational debate about the need of improving performance of public sector as a tool for Werlfare State empowerment.
\end{abstract}

Keywords: Administrative self-supply - Make or buy decisions in Public Sector - Spanish Act on Public Procurement - Administrative Law

$\left.{ }^{*}\right) \quad$ Nota del Editor: Este artículo fue recibido el 19 de febrero de 2021 y su publicación fue aprobada el 17 de abril de 2021.

${ }^{* *}$ Doctor en Derecho por Universidade da Coruña (La Coruña, España). Director de Cátedra de Derecho Local en Universidade da Coruña. Especialista en Derecho Administrativo. ORCID: https://orcid.org/0000-0002-2360-868X. Correo electrónico: casou@udc.gal 


\section{Objeto del presente trabajo}

El presente trabajo tiene como objeto situar a los lectores peruanos ante la actual situación en España de la regulación jurídica de lo que vamos a denominar "autoprovisión administrativa".

En una aproximación preliminar, este concepto jurídico trata de proporcionar un paraguas conceptual coherente al conjunto de técnicas de gestión administrativa mediante las cuales las Administraciones públicas pueden satisfacer entre sí las necesidades vinculadas al cumplimiento de sus misiones de servicio público.

A través de tres negocios típicos reconocidos en nuestro Derecho público -convenios de colaboración, encomiendas de gestión o encargos obligatorios- la finalidad de la autoprovisión es atender las necesidades del sector público dentro del propio sector público, esto es, contando con la capacidad de prestación de servicios que ofrecen las propias administraciones y sus personificaciones instrumentales, sin acudir al mercado en demanda de los bienes y servicios necesarios para atender el interés general a cuyo servicio las administraciones públicas se sitúan constitucionalmente.

Como puede observarse, la autoprovisión administrativa nos sitúa ante un problema o disyuntiva transversal de la acción administrativa global: lo que los anglosajones conocen como las make or buy decisions. El contenido y procedimiento de adopción de estas decisiones suelen estar configuradas por cada ordenamiento jurídico con una combinación de aspectos discrecionales y reglados. Esta combinación obedece a las tradiciones de cada país y, específicamente en nuestro contexto europeo, a las reglas de juego establecidas en las sucesivas Directivas de contratación pública de la Unión Europea.

Tales decisiones de "hacer" o "comprar" han constituido tradicionalmente un campo de conflicto entre las opciones soberanas de cada Estado miembro a la hora de configurar el funcionamiento de sus sectores públicos, y el desarrollo del mercado europeo interior de compra pública de bienes y servicios.
Durante los últimos veinte años, al menos, desde el famoso caso Teckal, resuelto por Sentencia del Tribunal de Justicia de la Unión Europea de 18 de noviembre de 1999, el árbitro de estas tensiones ha sido el Tribunal de Justicia de la Unión Europea, cuya jurisprudencia ha ido tejiendo una compleja madeja casuística de la materia(1). El corpus jurisprudencial generado en los últimos años podría caracterizarse de manera muy sumaria, por lo que ahora nos interesa, mediante tres rasgos distintivos:

- Su casuismo y heterogeneidad: el Tribunal interpreta la compatibilidad de un concreto derecho "operativo" nacional con las Directivas de contratación vigentes a la luz de casos concreto y, en algunas ocasiones, con el régimen de ayudas públicas. La proliferación de asuntos sometidos a la jurisdicción del TJUE ha configurado una jurisprudencia no siempre clara ni unívoca en su alcance, dadas las muchas particularidades que nacen de la coexistencia de 28 derechos administrativos nacionales distintos entre sí, y de las dificultades de traducción de sus avatares "patológicos" a las claves del derecho interno de otro Estado miembro(2).

- Una visión pancontractualista de la actividad administrativa, y de la definición misma de la noción europea de contrato público, cristalizada mediante la profundización casuística en los dos requisitos generales de la aplicabilidad de la autoprovisión o in house providing: un criterio subjetivo-organizativo (la existencia de "control análogo") y otro criterio funcional (que la misión dominante de la entidad adjudicataria sea servir a

(1) Los principales hitos de esta evolución han sido las sentencias del Tribunal de Justicia de 11 de enero de 2005, asunto Stadt Halle RPL Lochau (Asunto C-26/03); de 13 de octubre de 2005, asunto Parking Brixen (C-458/03); de 21 de julio de 2005, asunto Coname (C 231/03); de 19 de abril de 2007, asunto Tragsa (C-295/05); sentencia de 13 de noviembre de 2008, asunto Coditel Brabant (C324/07); de 9 de junio de 2009, asunto Hamburgo (C-480/06); sentencia de 10 de septiembre de 2009, asunto Sea Srl/Commune di Ponte Nossa (C-573/07); de 29 de noviembre de 2012, asunto Econord Spa; de 19 de diciembre de 2012, asunto Ordine degli Ingegneri della Provincia di Lecce (C-159/11); de 13 de junio de 2013, asunto Piepenbrock Dienstleistungen GmbH (C- 386/11); Sentencia de 8 de mayo de 2014 asunto Datenlotsen Informationssysteme GmbH (C-15/13; Sentencia de 19 de junio de 2014 , asunto Centro hospitalar de Setúbal y Such. (C-574/12); Sentencia de 11 de diciembre de 2014, asunto Azienda sanitaria locale (C-113/13); Sentencia de 8 de diciembre de 2016, asunto Cogesa SpA (C-553/2015); Sentencia de 21 de diciembre de 2016, asunto Remondis I (C-51/15).

(2) Véase en este sentido el trabajo de De la Sierra, S. (2016). Límites y utilidades del derecho comparado en el derecho público. En particular, el tratamiento jurídico de la crisis económico financiera. Revista de Administración Pública, 201, 69-99; y Boix, A. (2017) La europeización del Derecho administrativo español. En Martín, I.; Almeida, M. \& Di Lascio, F. (coords.), La europeización del derecho administrativo: una evaluación desde el ordenamiento español (pp. 35-108). Andavira. 
su entidad controladora, sin una vocación predominante de operar en el mercado) relacionado con la salvaguarda de una limpia concurrencia mercantil entre sector público empresarial y sector privado.

- La progresiva dulcificación de una interpretación originalmente estricta de estos criterios. Tendencia que tiene su cabo de las tormentas en un asunto español: el caso TRAGSA II de 19 de abril de $2007^{(3)}$. Especialmente, en materia de colaboración público-público esta evolución hacia una mayor permisividad puede contemplarse con suma claridad mediante la lectura yuxtapuesta de las sentencias del TJUE de 13 de enero de 2005 (recaída sobre la exclusión absoluta de los convenios de nuestra ley de contratos) ${ }^{(4)}$ y de 9 de junio de 2009 (asunto C-480/06, Comisión contra Alemania, más conocida como asunto Hamburgo) ${ }^{(5)}$.

Por la concurrencia de estos tres rasgos, los últimos años han sido de una profunda inseguridad sobre la consistencia comunitaria de dos grandes aspectos o dimensiones de nuestro derecho administrativo en sus tres niveles territoriales: (i) las formas organizativas (políticas de personificación instrumental) $y$, (ii) las formas operativas (políticas de gestión pública a través de convenios, contratos, encomiendas de gestión, etc.).

Frente a ello, el paquete de Directivas actualmente en vigor sobre contratación pública de 2014, tramitadas y aprobadas poco después de superar lo peor del crash financiero de 2008, han apostado por introducir una regulación específica más clara de las formas de cooperación dentro del sector público, admitiendo que tanto la denominada colaboración público-público vertical (mandatos administrativos obligatorios a formas públicas de personificación instrumental), como la colaboración público-público horizontal (convenios de colaboración) no se someten a las Directivas, siempre que cumplan con una serie de requisitos, cuyo contenido es el que las Directivas han armonizado ahora a nivel europeo.

Así pues, la dimensión europea de esta regulación interna es un rasgo insoslayable de la aproximación jurídica a esta materia en España. Dimensión que, sin embargo, está ausente en las regulaciones latinoamericanas.

\section{Las peculiaridades constitucionales del modelo peruano de compra pública}

Hecha la anterior presentación de lo que vamos a desarrollar en este trabajo, se hace necesario a continuación introducir una advertencia metodológica: siempre que se utiliza el canon del derecho comparado en cualquier trabajo jurídico-público, se impone como requisito previo la fijación, siquiera sea sumaria, del campo específico que va a funcionar como parámetro de referencia o comparación entre realidades jurídicas diversas.

En tal sentido, es de destacar la especificidad de las técnicas jurídicas

(3) Véase Janssen, V.A. (2014), The Institucionalised and Non-Institutionalised Exemptions from EU Public Procurement Law: towards a more coherent approach? Utrecht Law Review, 10(5), 180. Como consecuencia de esta sentencia, el Tribunal Supremo dictó la STS de 30 de enero de 2008 (RJ 2008/645)

(4) Esta sentencia condenó al Reino de España por excluir de forma absoluta del ámbito de aplicación del TRLCAP de 2000 los convenios de colaboración que celebren las Administraciones Públicas con las demás entidades públicas y, por tanto, también los convenios que constituyan contratos públicos a efectos de dichas Directivas, dando lugar a una reforma del artículo 3.1.c) del TRLCAP mediante Real Decreto-Ley 5/2005, de 11 de marzo, de reformas urgentes para el impulso a la productividad y para la mejora de la contratación pública. En este artículo se excluyen los convenios interadministrativos, salvo que la materia sobre la que versen sea objeto de un contrato de obras, de suministro, de consultoría y asistencia o de servicios cuyos importes sean superiores a las cuantías establecidas como umbral comunitario. Se estableció así una norma que pervive hasta hoy, y que hace girar la diferencia entre convenio y contrato alrededor del más que discutible criterio del objeto.

(5) En esta Sentencia, el Tribunal de Justicia "recuerda, en particular, que una autoridad pública puede realizar las tareas de interés público que le corresponden con sus propios medios sin verse obligada a recurrir a entidades externas y ajenas a sus servicios, y puede también hacerlo en colaboración con otras autoridades públicas (véase la sentencia Coditel Brabant, antes citada, apartados 48 y 49). (...) el Derecho comunitario no impone en modo alguno a las autoridades públicas el uso de una forma jurídica particular para garantizar sus misiones de servicio público conjuntamente. Por otro lado, tal colaboración entre autoridades públicas no cuestiona el objetivo principal de la normativa comunitaria sobre contratación pública, a saber, la libre circulación de los servicios y su apertura a la competencia no falseada en todos los Estados miembros, siempre que la realización de dicha cooperación se rija únicamente por consideraciones y exigencias características de la persecución de objetivos de interés público y se garantice el principio de igualdad de trato de los interesados contemplado en la Directiva 92/50, de manera que ninguna empresa privada se sitúe en una situación privilegiada respecto de sus competidores (véase la sentencia Stadt Halle y RPL Lochau, antes citada, apartados 50 y 51)". 
utilizadas por el Derecho público peruano, cuya lógica obedece a claves propias. Destacadamente, la regulación de esta materia aparece condicionada por la fuerza gravitatoria ejercida por el artículo 76 de la Constitución peruana de 1993. Un precepto de indudable importancia, porque entraña una constitucionalización del dogma neoliberal del contratista interpuesto que carece de parangón en el derecho europeo. En él se establece la "obligatoriedad de la contrata y licitación pública" en los siguientes términos: "Las obras y la adquisición de suministros con utilización de fondos o recursos públicos se ejecutan obligatoriamente por contrata y licitación pública, así como también la adquisición o la enajenación de bienes".

A pesar de ello, en Perú se mantiene la posibilidad (extra legem, por así decirlo) de realizar obras mediante ejecución directa de la propia Administración. En efecto, ante el silencio del Texto Único Ordenado de la Ley 30225 - Ley de Contrataciones del Estado, de 12 de marzo de 2019, tal opción se regula en un breve, y longevo, instrumento normativo de rango reglamentario, la Resolución de Contraloría N 195-88CG del 18 de julio de $1988^{(6)}$.

Además de lo anterior, el artículo 5 de la Ley de Contrataciones del Estado excluye de su ámbito de aplicación (y somete al control del Organismo Supervisor de las Contrataciones del Estado) los "convenios de colaboración u otros de naturaleza análoga, suscritos entre Entidades, siempre que se brinden los bienes, servicios u obras propios de la función que por Ley les corresponde, y no se persigan fines de lucro".

Si dirigimos la mirada al Texto Único Ordenado de la Ley 27444 (en adelante, TUO de la Ley 27444), de procedimiento administrativo general de Perú, el artículo 82 recoge la figura del "encargo de gestión", que equivale, mutatis mutandis, a nuestras "encomiendas de gestión". El artículo 82.4, con todo, recoge un fenómeno jurídico peculiar, como es que "mediante norma con rango de ley, puede facultarse a las entidades a realizar encargos de gestión a personas jurídicas no estatales, cuando razones de índole técnico y presupuestado lo haga aconsejable bajo los mismos términos previstos en este artículo, dicho encargo deberá realizarse con sujeción al Derecho Administrativo".
A su vez, el artículo 90 de esta Ley regula las denominadas "costas de colaboración" entre entidades que colaboran interinstitucionalmente mediante convenios de colaboración, de modo que el principio de gratuidad ["La solicitud de colaboración no genera el pago de tasas, derechos administrativos o de cualquier otro concepto que implique pago alguno, entre entidades de la administración pública" (art. 90.1 del TUO de la Ley 27444)], se matiza del siguiente modo: "A petición de la autoridad solicitada, la autoridad solicitante de otra entidad tendrá que pagar a ésta los gastos efectivos realizados cuando las acciones se encuentren fuera del ámbito de actividad ordinaria de la entidad" (art. 90.2 del TUO de la Ley 27444).

Hay en el Derecho público peruano, así pues, un abanico de posibilidades "materiales" de autoprovisión administrativa. Sin embargo, estas opciones carecen de una lógica jurídica común, y chocan con la mentalidad jurídica habitual de los operadores peruanos, en la que sigue predominando la visión pro empresarial de la satisfacción de las necesidades públicas que se deriva de su Constitución de 1993. Juan Carlos Morón Urbina nos ha dado cuenta de todo ello en esta misma revista con su trabajo "Las Obras por Administración directa y por encargo ¿Solución o problema? ¿Hay que restringirlas?"(7).

Paradójicamente, en España esta mentalidad es también mayoritaria, pero no por mandato constitucional, sino por la paulatina penetración del ordoliberalismo europeo en el conjunto de nuestros esquemas jurídicos.

(6) De su contenido, nos interesa retener cuatro aspectos:

1. Las Entidades que programen la ejecución de obras bajo esta modalidad, deben contar con la asignación presupuestal correspondiente, el personal técnico administrativo y los equipos necesarios.

2. Los Convenios que celebren las Entidades para encargar la ejecución de Obras por Administración Directa, deben precisar la capacidad operativa que dispone la Entidad Ejecutora a fin de asegurar el cumplimiento de las metas previstas.

3. Es requisito indispensable para la ejecución de estas obras, contar con el Expediente Técnico aprobado por el nivel competente, el mismo que comprenderá básicamente lo siguiente: memoria descriptiva, especificaciones técnicas, planos, metrados, presupuesto base con su análisis de costos y cronograma de adquisición de materiales y de ejecución de obra. En los casos que existan normas específicas referidas a la obra, se recabará el pronunciamiento del sector y/o Entidad que corresponda.

4. La Entidad debe demostrar que el costo total de la obra a ejecutarse por administración directa resulte igual o menos al presupuesto base deducida la utilidad, situación que deberá reflejarse en la liquidación de la obra.

(7) Véase Morón, J. (2016). Las Obras por Administración Directa y por encargo: ¿Solución o problema? ¿Hay que restringirlas? lus et Veritas, 53, 246-260. 


\section{El predominio de una hermenéutica (neoliberal) de la sospecha frente a la autoprovisión administrativa}

Aunque en España no existe ningún precepto legal precepto legal, ni constitucional, que afirme el dogma del contratista interpuesto, desde comienzos de siglo XXI, el trabajo conjunto del Tribunal de Justicia de la Unión Europea, la autoridad independiente de control de los mercados y la competencia (la Comisión Nacional de los Mercados y la Competencia) y los Tribunales de Cuentas estatal y autonómicos (Contralorías) ha ido arraigando lo que denomino una "lógica de la sospecha" contra las formas de autoprovisión administrativa.

Su comprensión mayoritaria entre la pléyade de juristas académicos y prácticos que se dedican a estas cuestiones (letrados de la Administración, interventores, auditores de cuentas públicas, jueces, miembros de los tribunales administrativos de contratación) es la de una excepción a la vis expansiva de la concurrencia mercantil propia del derecho comunitario de contratación pública, de modo que, como tal excepción, debe ser sometida a una interpretación jurídica restrictiva ${ }^{(8)}$. La regla general debe ser, pues, la de que las necesidades administrativas deben ser atendidas mediante el recurso a los mercados empresariales, a través de procedimientos de licitación abiertos y transparentes, que garanticen la mayor eficiencia al menor precio disponible.

En particular, cuando se habla de encargos obligatorios es frecuente que se parta de prejuicios previos, verosímiles, desde luego, pero no siempre contrastados con la realidad. Es la visión (ideológica, en cuanto que visión sesgada, abstracta y generalizante) de los encargos obligatorios como algo malo; bien como un subterfugio de huida del Derecho Administrativo(9), bien como una alteración de la libre concurrencia mercantil incompatible con el Derecho comunitario, bien como un foco de corruptelas e ineficiencias. Un escenario, en definitiva, de fallos de mercado y prácticas ineficientes de variado cariz, incluida la resiliente corrupción, que pone fácilmente en guardia tanto al crédulo del mercado como al santo inocente de la gestión administrativa.

Como testimonio de la influencia de estos sesgos, es particularmente significativo que se siga invocando el Derecho y la jurisprudencia comunitarias como fundamento de la visión excepcional de la autoprovisión, cuando el legislador comunitario, desde las Directivas de armonización de la contratación pública de 2014 ha apostado por una nueva formulación de la autoprovisión que aporta innovaciones destacables y un amplio margen para el desarrollo interno por los Estados miembros.

A pesar de ello, el enfoque del legislador español de contratos, plasmado en la Ley 9/2017, combina un apego literal al texto de las directivas con unos desarrollos propios que obedecen más a la inercia de esa política jurídica "desconfiada", en cuyo interior laten distintos sesgos ideológicos que, de tan familiares y frecuentes, han pasado a gozar de la invisibilidad de lo obvio.

Hoy, sin embargo, tales sesgos hermenéuticos se han convertido un obstáculo para la correcta comprensión del material jurídico vigente. Nuestro país se caracteriza, en este sentido, por la gran distancia que existe entre su práctica administrativa, en la que la autoprovisión es utilizada frecuentemente y con normalidad por múltiples actores político-administrativos, y esa cultura jurídico administrativa dominante.

(8) Véase en este sentido los trabajos de Gimeno Feliú, J. M. (2006). La nueva contratación pública europea y su incidencia en la legislación española. Thomson Civitas, en especial las páginas 127-151; Fuertes, M. \& Sosa, F. (2007) ¿Pueden los contratos quedar en casa? La polémica europea sobre la contratación in house. Diario La Ley, 6.715; González, J. (2007). Medios propios de la Administración, colaboración administrativa y sometimiento a la normativa comunitaria de contratación. Revista de Administración Pública, 173, 217-237; Berna, M. (2008). Un paso en falso en la interpretación del criterio del control análogo al de los propios servicios en las relaciones in house. Comentario a la STJUE de 19 de abril de 2007. Revista Española de Derecho Administrativo, 137, 115138; Noguera, B. (2010). Los encargos in house en la Ley de Contratos del Sector Público. Especial referencia a los mismos en el ámbito local a la luz de la reciente jurisprudencia comunitaria. Revista de Administración Pública, 182, 159-190; Pernas, J.(2008). Las operaciones in house y el Derecho comunitario de contratos públicos: análisis de la jurisprudencia del TJCE. Iustel; Montoya, E. (2011). La delimitación de los encargos domésticos: presupuesto para evitar la huida de las garantías de la contratación pública. En F. López (coord.). Derechos y garantías del ciudadano: estudios en homenaje al profesor Alfonso Pérez Moreno (pp. 859-907). lustel; más recientemente, véase Gallego, I. (2015). Los encargos a medios propios y servicios técnicos en la jurisprudencia del TJUE. Contratación Administrativa Práctica, 140, 70-78.

(9) Desde el punto de vista de la "huida del Derecho Administrativo" hacia unos esquemas de funcionamiento administrativo menos garantistas y transparentes y, por ende, más abierto a las frecuentes patologías de nuestras Administraciones (clientelismo, precarización laboral, corrupción, etc.). Véase Amoedo-Souto, C. (2004). Tragsa. Medios propios y huida del Derecho Administrativo. Atelier; Cuadros, M. (2014). Patologías en el empleo público: el caso Tragsa. Nueva revista española de derecho del trabajo, 168, 305-334. 


\section{La prestación interadministrativa de servicios en España: una realidad resiliente}

Especialmente a partir de la segunda mitad del siglo $X X$, el sector público ha venido prestando una gran cantidad de servicios a la ciudadanía. De hecho, lo viene haciendo de manera habitual, como expresan, sin ir más lejos, las técnicas tributarias de las tasas y los precios públicos, cuyos objetos imponibles no son sino la prestación de servicios que pueden o no tener su correspondiente correlato en el sector privado.

Hoy, con un simple vistazo a los catálogos actualizados de tasas y precios públicos en los portales de transparencia de las administraciones, podremos contemplar la cantidad y variedad de servicios prestados y bienes proporcionados desde el sector público a la ciudadanía en general.

Pero en determinados casos, las Administraciones, en particular, aquellas especializadas en el desarrollo de una determinada actividad, han venido también prestándose servicios entre ellas. Desde la recaudación de tributos municipales realizada por una Diputación para un ayuntamiento, hasta la fabricación de un navío de guerra, pasando por la realización de caminos de concentración parcelaria, el saneamiento ganadero, la consultoría en ingeniería o arquitectura, la realización de un control metrológico o la venta de inmuebles desafectados del servicio público, la provisión interadministrativa de bienes, suministros y servicios ha venido siendo un fenómeno habitual en nuestro país.

Gráfico sobre la evaluación (acumulado) del número de entidades que adquieren la condición de medio propio en los ámbitos estatal y autonómico.

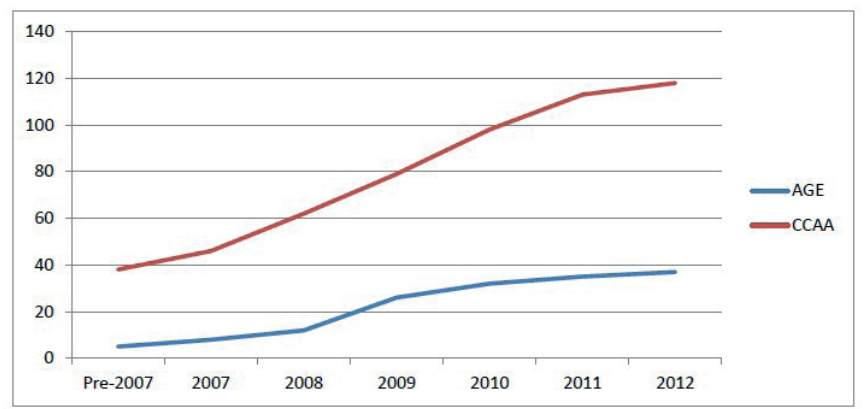

Fuente: Elaboración propia con datos del BOE. Boletines oficiales autonómicos y directorios de empresas públicas de algunas CCAA.

El Informe de la Comisión Nacional de los Mercados y la Competencia de 19 de junio de 2013, titulado "Los medios propios y las encomiendas de gestión: implicaciones de su uso desde la óptica de la promoción de la competencia", calcula que el número de medios propios -personificaciones instrumentales de derecho público o derecho privado, como empresas mercantiles o fundaciones- vinculados a la Administración General del Estado (AGE) y de las Comunidades Autónomas, asciende a 155,37 estatales y 118 autonómicos. Se constató un incremento de su uso a partir de 2007, coincidiendo con el inicio de la crisis económica.

Estas entidades se encuentran activas en los más variados sectores de la actividad económica, entre otros: consultoría técnica, ejecución de obra civil, militar, agraria o forestal, servicios de certificación electrónica, promoción exterior o edición de medios escritos a través de la Agencia Estatal Boletín Oficial del Estado.

Recientemente, el 5 de noviembre de 2020, la Intervención General de la Administración del Estado (IGAE) aprobó el "Informe de la Intervención General del Estado relativo a los principales resultados de control en materia de contratación pública conforme al artículo 332.11 de la LCSP", para su remisión a la Oficina Independiente de Regulación y Supervisión de la Contratación (OIRESCON). Este informe diagnostica la utilización de encargos obligatorios a medios propios personificados en la Administración General del Estado, ya bajo la vigencia de la Ley 9/2017, de contratos del sector público, y nos proporciona datos oficiales actualizados sobre la realidad de estos encargos en la Administración General del Estado. Constituye, por tanto, una radiografía de la situación actual de la operativa con encargos obligatorios en esta Administración.

Así, los 5 mayores medios propios estatales (TRAGSA, TRAGSATEC, FNMTRCM, ISDEFE e INECO) facturaron en 2019 un total de 1.020 millones de euros.

En el caso de los poderes adjudicadores "Administración Pública" analizados por la IGAE, más del $50 \%$ del importe de los encargos se ha ejecutado por dos medios propios: FNMT-RCM, $(22,44 \%)$ y TRAGSATEC $(24,18 \%)$. INECO supone un $17,41 \%$ y el resto (18 medios propios) está por debajo del $10 \%$ cada uno de ellos. 
TRAGSATEC, ISDEFE e INECO sólo han ejecutado encargos de servicios, mientras que la FNMT-RCM ejecuta mayoritariamente encargos de suministros.

En el caso de los poderes adjudicadores Administración Pública analizados por la Intervención General del Ministerio de Defensa, ISDEFE ha ejecutado más de $90 \%$ del importe de EMP en este ámbito.

El volumen de encargos obligatorios realizados a los medios propios estatales en el período analizado ( 9 de marzo de 2018 a 30 de abril de 2019) alcanzó los 800 millones de euros, repartidos entre la administración general del Estado (710 millones) y el Ministerio de Defensa (90 millones).

Si descontamos el efecto obras, el porcentaje de operativa con encargos sobre contrataciones se eleva en la AGE al $34 \%$, frente al $1,27 \%$ del Ministerio de Defensa. En el informe se concluye que "Prácticamente todos los departamentos ministeriales y gran parte de los organismos públicos recurren a este negocio jurídico por lo que la especificidad inicial de esta figura ha desaparecido para situarse en el tablero de opciones para el gestor público de una forma muy significativa" (página 28 del Informe).

La "normalización" de la autoprovisión administrativa como alternativa gestora no es coyuntural. Al contrario. Se trata de una alternativa "resiliente", directamente relacionada con las rigideces y carencias endémicas de nuestras administraciones. En particular, no puede explicarse sin tener en cuenta fenómenos tan arraigados como la escasa dotación de personal público, los costes de oportunidad en la gestión de los procedimientos administrativos abiertos de adjudicación de contratos, o las propias malas prácticas de los contratistas de las Administraciones ("adicción al modificado", dilación en el cumplimiento de plazos de ejecución, tendencia a la captura de rentas públicas, etc.).

No es de extrañar, pues, que en una época que ha hecho de la eficiencia necesidad y virtud, la apuesta por la autoprovisión administrativa mediante el recurso a medios propios instrumentales se haya incrementado en el Reino de España, al margen de una regulación jurídica todavía tributaria de la visión de estas técnicas como una excepción.

\section{La nueva regulación básica de la autoprovisión administrativa en la Ley 9/2017, de contratos del sector público: una escala en tránsito}

La nueva Ley 9/2017, de 8 de noviembre, de contratos del sector público (LCSP), ha sido la norma básica encargada de trasponer a nuestro ordenamiento interno los artículos 17 y 12 de las Directivas 23 y 24/2014. En ella debemos buscar los materiales normativos con los que construir el actual régimen jurídico básico común de la autoprovisión en España.

Con todo, es necesario tener presente que la autoprovisión en los denominados sectores excluidos (agua, energía, transportes y servicios postales) conforma un régimen básico especial, cuya relevancia no es menor.

Tras años de bloqueo parlamentario, la Directiva 25/2014 ha sido finalmente transpuesta a nuestro ordenamiento interno mediante un Real Decreto-ley: el 3/2020, de 4 de febrero. Con esta publicación en una norma de origen gubernamental, se ha pretendido evitar que recayese sentencia condenatoria contra el Reino de España por falta de trasposición de la Directiva $25^{(10)}$. El Libro Primero de este Real Decreto-Ley se dedica a recoger las normas de trasposición -126 artículos- de la Directiva 25, cuya entrada en vigor el día 5 de marzo de 2020 ha derogado la homóloga Ley 31/2007.

Del grupo normativo que acabamos de describir, cuatro son los rasgos jurídicos que nos interesa destacar en este momento. En una primera lectura transversal del conjunto de este material normativo, parece evidente que el criterio general seguido por el legislador

(10) La Comisión Europea impuso multas coercitivas a los Estados miembros que no traspusieron correctamente la Directiva 25. Vid. en este sentido el Recurso interpuesto el 6 de febrero de 2018 por la Comisión Europea contra la República de Austria, Asunto C-76/18, y el interpuesto el 7 de febrero de 2018 contra Luxemburgo, Asunto C-88/18. El 7 de diciembre de 2017 la Comisión Europea interpuso contra el Reino de España dos recursos ante el Tribunal de Justicia de la Unión Europea para que declarase que España ha incumplido las obligaciones de trasposición de la Directiva 25. Precisamente por ello, en las palabras del Preámbulo del Real Decreto-Ley 3/2020, "Ante la gravedad de las consecuencias de seguir acumulando retraso en la completa incorporación al ordenamiento jurídico español de las citadas Directivas, y en cumplimiento de la Decisión del Consejo de 2016, resulta imprescindible acudir a la aprobación de un real decreto ley para proceder a su transposición urgente, lo que previsiblemente determinará que los recursos por incumplimiento interpuestos por la Comisión Europea ante el Tribunal de Justicia de la Unión Europea decaigan por pérdida de su objeto y, en cualquier caso, debería evitar la imposición de sanciones económicas a España, al haber solicitado la Comisión Europea la imposición de multas coercitivas diarias". Así se ha justificado la utilización de un Real Decreto Ley como norma de trasposición. 
español ha sido la trasposición literal de los tres criterios de las Directivas de 2014 conforme a los cuales la realización de encargos de cooperación vertical y las operaciones de colaboración horizontal resultan compatibles con el Derecho comunitario de contratación pública.

La nueva LCSP desarrolla el afán comunitario de incorporar y regular con pormenor distintas técnicas no contractuales de autoprovisión administrativa. Esto es, de regular los criterios cuya presencia hacen posible generar negocios jurídicos destinados a la satisfacción dentro del sector público de las necesidades de bienes y servicios destinados a la atención de las misiones de servicio público de la competencia de cada administración, sin por ello alterar el funcionamiento del libre mercado(11).

Sin embargo, como veremos, el legislador básico ha optado por aplicar una característica lectura interna restrictiva de las técnicas de autoprovisión, que no se deduce directamente de las Directivas. La tradicional lógica de la sospecha se ha mantenido como telón de fondo inspirador del actual enfoque regulatorio.

En tercer lugar, esta lectura interna restrictiva ha sido desarrollada mediante dos movimientos complementarios: el aumento de la densidad normativa de los preceptos legales dedicados a la autoprovisión vertical (art. 32 y 33 LCSP), continuando la combinación de aspectos "contractuales" comunitarios con los aspectos "organizativos" internos que se incorporaron en su día en la Ley de contratos del sector público de 2007. Ello ha creado una normativa básica abigarrada y compleja que, paradójicamente, ha generado más incertidumbres que certezas.

En particular, la legislación básica contractual actual debe ser observada por todas las administraciones territoriales y sus personificaciones jurídicas, aunque las entidades locales gocen de normas específicas contenidas en la Ley de Bases de Régimen Local, y las Comunidades Autónomas gocen de la potestad de desarrollo y adaptación conforme a sus propios criterios de oportunidad político-administrativa en materia de autoorganización. De ahí que, junto a la legislación básica contractual preexistan y coexistan normas legales autonómicas y de ámbito local reguladoras de operaciones de autoprovisión administrativa, habilitadas por títulos competenciales específicos, cuyo régimen de eficacia normativa respecto de la LCSP demanda una interpretación sistemática coherente que no siempre resulta fácil.

Un cuarto aspecto relevante es la inestabilidad e inseguridad jurídica del cuadro jurídico resultante. Ello se deriva, a su vez, de la confluencia de tres aspectos clave:

- El hecho de no haberse desarrollado reglamentariamente los múltiples aspectos operativos que los artículos 32 y 33 LCSP han dejado abiertos en un ámbito de actuación administrativa sometido, como sabemos, a una "lógica de la sospecha". Apenas se han producido desarrollos mediante instrucciones e informes de los órganos de fiscalización de la Administración General del Estado. Documentos carentes de valor normativo para el resto de niveles territoriales de gobierno, pero que han actuado como una especie de soft law para el conjunto del sector público.

- La modificación sobrevenida de los artículos 32 y 33 en cuatro ocasiones: en apenas 3 años de vigor, la redacción original de estos dos artículos ha sido alterada posteriormente en cuatro

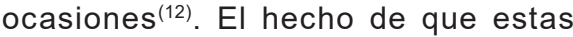

(11) La doctrina se ha ocupado de interpretar sistemáticamente estos preceptos. Deben señalarse en este sentido los trabajos de Lozano Cutanda, B. \& Lozano Puyol, I. (2017). Los nuevos requisitos de la contratación in-house previstos en el Proyecto de Ley de Contratos del Sector Público y en la Ley 40/2015. Contratación Administrativa Práctica, (148); Alemany, J. (2017). Los encargos a sociedades mercantiles de capital integramente público como medios propios en la legislación actual. Atelier; Fernández-Figares, L. M. (2017). Los encargos a medios propios en la legislación actual: Texto adaptado a las leyes 39 y 40/2015 y al Proyecto de Ley de Contratos del Sector Público. Editorial Reus; Amoedo-Souto, C. A. (2018). Los encargos a medios propios e instrumentales. ¿Hacia un nuevo comienzo? En J. M. Gimeno Feliú (coord.), Comentarios a la Ley 9/2017, de contratos del sector público (pp. 369-410). Thomson Reuters Aranzadi; Amoedo-Souto, C.A. (2018). Autoprovisión administrativa. Dimensión europea y desajustes internos. Revista de Administración Pública, 205, 81-129; Amoedo-Souto, C.A. \& Cutrín, M. (2019). El impacto de la Ley 9/2017, de contratos del sector público, en la gestión directa de servicios públicos locales a través de medios propios. Revista de Administración Pública, 210, 393492; Noguera de la Muela, B. (2018). Cooperación vertical: los encargos a medios propios o servicios técnicos. En E. Gamero, I. Gallego (coord.), Tratado de Contratos del Sector Público (Tomo I, pp, 667-712). Tirant Lo Blanch.

(12) Se trata de modificaciones contenidas en la Ley 6/2018, de 3 de julio, de presupuestos generales para 2018; el Real Decreto-ley $17 / 2020$, de 5 de mayo, por el que se aprueban medidas de apoyo al sector cultural y de carácter tributario para hacer frente al impacto económico y social del COVID-2019; la Ley 11/2020, de 30 de diciembre, de presupuestos generales del Estado para 2021, y por el Real Decreto-ley 36/2020, de 30 de diciembre, por el que se aprueban medidas urgentes para la modernización de la Administración Pública y para la ejecución del Plan de Recuperación, Transformación y Resiliencia. 
modificaciones se hayan incluido en leyes de presupuestos y reales decretos leyes nos ha sustraído la posibilidad de conocer satisfactoriamente las razones que han motivado estos cambios, y a sus protagonistas o promotores.

- El carácter dinámico de la jurisprudencia comunitaria del TJUE, cuya interpretación sigue realizándose con carácter mayoritario en términos restrictivos de la autoprovisión administrativa.

Hechas estas consideraciones generales, podemos pasar ya a describir someramente el contenido de la LCSP.

Las técnicas de autoprovisión dentro del sector público se detallan dentro del capítulo de la Ley destinado a regular la racionalidad y consistencia de la contratación del sector público. Esta ubicación refleja la voluntad del legislador de enfocar el conjunto de técnicas de autoprovisión dentro del sector público en una perspectiva de eficiencia y consistencia del recurso a la externalización contractual.

La primera técnica de autoprovisión que encontramos es un contenido clásico de las leyes de contratos: la ejecución de obras, suministros y servicios por la propia Administración.

Estamos ante los encargos obligatorios de prestaciones a servicios administrativos no personificados, esto es, encargos de autoprovisión estrictamente intra administrativa en los que no hay, stricto sensu, una cooperación pública entre dos o más sujetos público administrativos.

Su regulación se incluye ahora en el artículo 30, y mantiene sus dos modalidades tradicionales de ejecución:

- Con servicios propios - esto es, integrados en la estructura orgánica administrativa y no segregados mediante personificación independiente.

- Con colaboración de empresarios particulares.

La regulación es muy similar a la anterior, y sigue conservando su carácter no básico ${ }^{(13)}$, de modo que sigue dejando un amplio espacio normativo para las Comunidades Autónomas (aunque las Comunidades no hagan uso de sus potestades normativas al respecto); pero se incorporan algunas mejoras de redacción menores ${ }^{(14)}$, y las siguientes dos novedades de interés:

a) Desaparición del umbral máximo de ejecución directa de obras. Ha desaparecido el umbral económico máximo de ejecución de obras por la propia administración, que estaba situado en 5.225.000 € (el importe a partir del cual estábamos en contrato de obras sujeto a regulación armonizada).

b) Introducción de una regla de racionalización de la ejecución directa de servicios. En materia de realización de servicios, el párrafo tercero incorpora una relevante regla de racionalización de la contratación, que complementa lo previsto por el artículo 28, y que deberán observar los órganos de contratación de la Administración General del Estado: "La prestación de servicios se realizará normalmente por la propia Administración por sus propios medios".

$Y$ "cuando carezca de medios suficientes", cuestión que habrá que motivar en el expediente de contratación, de conformidad con el artículo 28 y 116, se podrá acudir a la contratación externa, de conformidad con lo establecido por los artículos 306 y siguientes ${ }^{(15)}$.

De tal manera que la primera regla del gestor en la administración general del Estado es la autoprovisión de servicios, y la regla subsidiaria, la externalización de su satisfacción al mercado ${ }^{(16)}$.

(13) Tal y como hacía la disposición final segunda del TRLCSP de 2011, que consideraba no básico el artículo 24 en sus apartados 1 a 5 , la disposición final primera de la LCSP no considera básico el artículo 30.

(14) Los supuestos de ejecución directa en los que es obligatorio redactar "el correspondiente proyecto".

(15) Nótese que. en la dicción de la ley, se dice "por sus propios medios". No se dice "por sus medios propios", expresión que denotaría un significado técnico más preciso. Por la amplitud de la expresión "por sus propios medios", cabría considerar posible la inclusión de técnicas de autoprovisión en el sector público para satisfacer estas necesidades. De hecho, esto es un campo abierto a una más precisa regulación autonómica: concretar qué se consideran a estos efectos medios de la Administración capaces de satisfacer sus necesidades de manera eficiente dentro del propio sector público.

(16) Téngase en cuenta, no obstante, que el artículo 86.2 de la Ley 40/2015 ha abonado una interpretación contraria a esta, para cuya expresión vale la cita de Marc Villalta Reixach: “(...) la LRJSP limita notablemente la libertad organizativa que había venido caracterizando hasta ahora la utilización por la Administración de los encargos a medios propios, introduciendo una especie de presunción de ineficacia de la actuación pública y un claro criterio de subsidiariedad de ésta respecto al mercado. De modo que, a no ser que se demuestre expresamente que la autoprovisión es una opción más eficiente, eficaz y sostenible, todos aquellos encargos de actividades contractuales susceptibles de explotación privada deberán ser, inicialmente, objeto de un procedimiento de licitación" (Véase Villalta, M. (2017). La encomienda de gestión en la LRJSP. Régimen jurídico y distinción de figuras afines. En Estudios sobre las leyes 39/2015 del procedimiento administrativo común de las administraciones públicas y 40/2015 del régimen 
El legislador parte aquí de la presunción de que es más eficiente la autoprovisión que la externalización, pues sólo admite la externalización por la razón objetiva de insuficiencia de medios.

De ello se deriva también que, cuanto más objetiva sea esa insuficiencia, más fácil será motivar la externalización contractual; y cuantos más medios tenga a su disposición la Administración, más tendrá que esforzarse el gestor en motivar su externalización para que pase la fiscalización del correspondiente servicio interventor del gasto.

A continuación, el artículo 31 representa lo que podemos denominar el precepto esquema de la autoprovisión cooperativa: fija los conceptos jurídicos generales de su definición, y traza el mapa de las posibles formas de autoprovisión mediante cooperación pública entre entidades pertenecientes al sector público.

Los conceptos jurídicos generales son los siguientes:

- La autoprovisión cooperativa se configura como una opción autoorganizativa.

- Como tal, cabe atribuirle la amplia discrecionalidad propia de las opciones de autoorganización. El artículo 31 omite cualquier regla específica que condicione la selección de las formas de autoprovisión cooperativa.

- La autoprovisión cooperativa es una opción disponible para todas las entidades del sector público, sean o no poderes adjudicadores en sentido contractual.

- El "resultado" de la autoprovisión cooperativa no es contractual.

Para cooperar en el cumplimiento de sus respectivas misiones de servicio público, en el uso de su potestad de auto organización las entidades pertenecientes al sector público pueden cooperar de tres maneras:

a) Mediante sistemas de cooperación vertical consistentes en el uso de medios propios personificados en el sentido y con los límites establecidos en el artículo 32 para los poderes adjudicadores, y en el artículo 33 para los entes del sector público que no tengan la consideración de poder adjudicador, mediante el oportuno acuerdo de encargo.

Se establecen pues dos regímenes en función de si el ente del sector público encomendante recibe o no la calificación de poder adjudicador, calificación que dependerá del juicio singular, y no pocas veces difícil, de contraste de los criterios previstos a tal efecto por el artículo 3 para la inclusión en el sector público (art. 3.1) y la exclusión de la noción de poder adjudicador (art. 3.3).

En todo caso, dada la complejidad de los artículos 32 y 33, nos limitaremos a enunciar su clave de comprensión regulatoria, que puede resumirse en la siguiente regla básica: "El encargo que cumpla dichos requisitos no tendrá la consideración de contrato" (art. 32.1.in fine) $)^{(17)}$.

Dicho sea, negativamente: si un concreto encargo obligatorio no cumple las reglas establecidas por el artículo 32, deberá merecer la consideración de un verdadero contrato público. Con todo, la LCSP no acaba de ser contundente en derivar consecuencias jurídicas de tal "levantamiento del velo", pues no anuda en tales casos la sanción de nulidad, sino de mera anulabilidad del encargo "fraudulento".

b) Mediante sistemas de cooperación horizontal entre entidades pertenecientes al sector público, previa celebración de los correspondientes convenios, en las condiciones y con los límites que se establecen en el apartado 1 del artículo 6 LCSP.

Al tradicional límite de nuestra legislación, que el contenido de los convenios no coincida con el de los contratos típicos, el artículo 6 ha añadido los tres nuevos requisitos, acuñados por la jurisprudencia comunitaria $^{(18)}$ y concretados en los artículo 12.4 y 17.4 de las Directivas 24 y 23 :

- Que las entidades intervinientes no tengan vocación de mercado, introduciendo

jurídico del sector público (pp. 77-105). Atelier.) Opino, sin embargo, que los contenidos que comentamos de la LCSP/2017, como ley posterior, obligan cuando menos a matizar esta valoración.

(17) El artículo 32.6 reitera de nuevo la regla del artículo 32.1.in fine: "Los encargos que realicen las entidades del sector público a un ente que, de acuerdo con los apartados segundo, tercero o cuarto de este artículo, pueda ser calificado como medio propio personificado del primero o primeros, no tendrán la consideración jurídica de contrato".

(18) Véase sentencias TJUE Comisión contra Alemania, asunto C-480/06; Azienda Sanitaria Locale di Lecce, asunto C-159/11, Piepenbrock, asunto C-386/11. 
aquí la regla cuantitativa prevista por el artículo 12.4 de la Directiva: se presume la existencia de vocación de mercado cuando la entidad colaboradora realice en el mercado abierto un porcentaje igual a superior al $20 \%$ de las actividades objeto de colaboración.

- Que el convenio establezca o desarrolle una cooperación entre las entidades participantes con la finalidad de garantizar que los servicios públicos que les incumben se prestan de modo que se logren los objetivos que tienen en común.

- Que el desarrollo de la cooperación se guie únicamente por consideraciones relacionadas con el interés público.

c) Mediante realización conjunta de contrataciones esporádicas. Se trata de un nuevo contenido del precepto, introducido mediante enmienda en el Congreso de los Diputados ${ }^{(19)}$, que traspone la previsión del artículo 38 de la Directiva 2014/24 sobre contratación conjunta esporádica. Aunque no se especifica cómo se debe instrumentar jurídicamente estas contrataciones esporádicas, todo apunta a la necesidad de un convenio o acuerdo de colaboración.

En definitiva, lejos de aumentar la seguridad jurídica y la trazabilidad de estas operaciones de cooperación, la Ley de Contratos del Sector Público de 2017 ha profundizado en los enfoques jurídicos habituales de los últimos veinte años, absorbiendo para sí una regulación muy parcial, que no abarca satisfactoriamente las múltiples dimensiones de la autoprovisión: lo organizativo, las modalidades de gestión que comportan, el plano concurrencial, las patologías laborales, su régimen tributario. De modo que nos encontramos con una cada vez mayor disociación entre el derecho administrativo y la realidad político-administrativa, entre el derecho positivo y el derecho realmente aplicado ${ }^{(20)}$. En este sentido, se puede afirmar que la Ley 9/2017 se corresponde con una fase en tránsito, en la que la visión tradicional no acaba de superarse, ni se vislumbra claridad regulatoria acorde con los desafíos presentes.
Ello provoca la suficiente inseguridad jurídica como para que se desincentive la innovación en la utilización de las fórmulas de autoprovisión administrativa. Al hacerlo, se están desaprovechando muchas de sus potencialidades para satisfacer los intereses generales. De ahí que quien esto escribe venga reclamando desde hace años la necesidad de elaborar y aprobar una ley básica de autoprovisión administrativa, en la que se regulen con detenimiento y visión de conjunto todos los aspectos jurídicos (organizativos, concurrenciales, operativos, de gestión del personal, tributarios, etc.) que conforman hoy la realidad magmática de la autoprovisión administrativa.

Esta visión estratégica de la autoprovisión administrativa es inseparable de una reflexión sobre el futuro de la acción administrativa y, en particular, sobre el papel que el sector público debe jugar en el fortalecimiento del Estado de Bienestar en las sociedades avanzadas del siglo XXI.

\section{Final. El debate sobre la autoprovisión administrativa en perspectiva}

Tal y como aquí se aborda, la autoprovisión administrativa ofrece un marco conceptual en el que situar adecuadamente esas realidades administrativas presentes de una u otra forma en el desarrollo de la acción administrativa de muchos países, no sólo europeos.

Es necesario enfocar estratégicamente las técnicas de autoprovisión administrativa para resituar en nuestro Derecho interno de

(19) En concreto, la enmienda núm. 38, del G.P. Confederal de Unidos Podemos-En Comú Podem En Marea, cuya justificación es la siguiente: "Se trata de trasponer de una forma más completa y adecuada el artículo 38 de la Directiva 2014/24, del Parlamento Europeo y del Consejo, sobre contratación pública, para que quede más y mejor clarificada la posibilidad de la contratación conjunta esporádica, lo que sin duda conviene fomentar especialmente entre Entidades Locales, pero también entre las demás entidades del sector público, en aras de una mayor eficiencia en la contratación. Para ello es necesario también numerar el artículo y dividirlo en tres apartados" ${ }^{20}$ Valgan dos ejemplos. El artículo 56 de la Ley gallega 1/2015, de calidad de los servicios públicos y de la buena administración, regula los denominados "convenios de colaboración para la cogestión", para el caso de aquellos servicios públicos que sean prestados mancomunadamente por dos o más administraciones. Por su parte, el artículo 15 de la Ley gallega 14/2013, de racionalización del sector público autonómico, regula con detalle los "acuerdos de colaboración o cooperación para la financiación conjunta de contratos para la satisfacción de una finalidad común".

(20) Disociación recientemente evocada por Antonio Jiménez-Blanco, A. (2018). Coloquio de clausura "El futuro del Derecho Administrativo", Sciences Po (París), Cátedra Mutaciones de la Acción Pública y del Derecho Público, 21 y 22 de junio de 2018. Revista de Administración Pública, 207, 319-343. 
una manera más coherente las posibilidades incorporadas a las Directivas de contratación de 2014 y a la nueva Ley 9/2017, de 8 de noviembre, de Contratos del Sector Público.

Detrás de esta nueva regulación comunitaria se encuentra, a nuestro juicio, una reacción ante las políticas neoliberales de los últimos veinticinco años, que han visto en la expansión del mercado interior una suerte de varita mágica y que, correlativamente, han considerado que los servicios públicos eran una anomalía del mercado que, como tal, debía reducir su alcance e interpretarse restrictivamente, para así permitir la incorporación de sus objetos a la lógica -presuntamente más virtuosa- del libre juego de la oferta y la demanda de mercado.

Frente a ello, la profunda crisis económica iniciada el año 2008 inició una toma de conciencia sobre la necesidad de contener la libre expansión de una lógica de mercado que, al alcanzar una dimensión global, ha mutado en lo que Luigi Ferrajoli (21) ha denominado un "poder salvaje": un amenazante poder, no sometido a regulación, limitación o control suficientemente sólidos, que por ello mismo está poniendo en jaque la preeminencia de los valores superiores proclamados por los textos constitucionales. En muy primer lugar, la dignidad de la persona humana y los derechos fundamentales que de ella se derivan, pero también la propia autogestión democrática de las sociedades contemporáneas a través de sus instituciones políticas.

No es de extrañar, pues, que ante el fracaso de los intentos de regulación global del mercado (lucha contra los paraísos fiscales, tasa a las transacciones financieras, reducción de los gases con efecto invernadero del Protocolo de Kioto, etc.) desde distintas sensibilidades políticas se hayan planteado dos grandes tipos de respuestas: por un lado, respuestas unilaterales de tipo neoproteccionista, como la ensayada -con medidas contradictorias y pírricos resultados- por la Administración Trump en Estados Unidos; por otro lado, una estrategia de "vuelta a lo público" en la satisfacción de las necesidades y demandas sociales que vaya más allá de la táctica defensiva frente a los recortes del Estado de Bienestar, y que de alguna manera ofrezca un anclaje más sólido a los Estados nacionales frente a la imparable expansión de la globalización económica. Esta es la respuesta predominante en la izquierda europea ${ }^{(22)} \mathrm{y}$, con matices, de la norteamericana.

Recientemente, el Nobel de Economía de 2001 Joseph E. Stiglitz ha defendido la "opción pública", la posibilidad de que el Estado ofrezca una serie de servicios que implique más competencia e innovación, baje precios y haga más fácil la vida a los ciudadanos ${ }^{(23)}$. También Eric Olin Wright ha propuesto la necesidad de rearmar las capacidades prestacionales de bienes y servicios del Estado como palanca para domesticar y, a la postre, erosionar las dinámicas nocivas de un capitalismo librado a su propia lógica agonística, posibilitando así la profundización en la lógica económica del socialismo democrático ${ }^{(24)}$.

Priorizar la satisfacción de ciertas necesidades públicas dentro del sector público, y no desde la concurrencia de mercado constituye, pues, una tendencia de fondo que se enmarca dentro de ese contexto más general, ofreciendo respuestas concretas y operativas a tal empeño.

Es importante reparar en la variedad de consecuencias de esta priorización. Mediante la autoprovisión administrativa, el gasto público que una administración debe realizar para obtener una obra, bien o servicio, se convierte en el ingreso público de otra rama del sector público. La autoprovisión supone en este sentido una apuesta por la economía circular del sector público, dentro de la cual las demandas de bienes y servicios públicos de las administraciones se satisfacen sin acudir al mercado privado, aprovechando los múltiples recursos que ofrecen las propias administraciones, ya sea directamente, ya

(21) Véase Ferrajoli, L. (2011). Poderes salvajes. La crisis de la democracia constitucional. Trotta.

(22) Véase el informe elaborado en mayo de 2012 por la Unidad de Investigación Internacional de Servicios Públicos de la Universidad de Greenwich, por encargo de la Federación sindical europea de los servicios públicos, disponible en español en el site https:/l www.epsu.org/sites/default/files/article/files/remunicipalizacion_y_servicios_municipales_DH-2.pdf. Algún autor ha denominado este proceso como "insourcing", para oponerlo al "outsourcing". Véase. Wollmann, H. (2013). La experiencia de los ordenamientos europeos: ¿un retorno a las gestiones públicas/municipales? Cuadernos de Derecho Local, (31), 76. En palabras de Athanasios Gromitsaris, "there is evidence that there is a trend in different countries in Europe towards provisions by services by the public sector, i.e., towards bringing service provisions back "home" (in-house) or towards "re-municipalisations". (véase Gromitsaris, A. (2013). New public management: a new common european tradition. En M. Ruffert (ed.), Administrative Law in Europe: between common principles and national traditions (p. 197). Europa Law Publishing).

(23) Véase.Stiglitz, J. E. (2020). Capitalismo progresista. La respuesta a la era del malestar. Taurus, en especial pp. $190-211$.

(24) Véase Wright, E. (2020). Cómo ser anticapitalista en el siglo XXI (pp. 103-106). Akal. 
a través de sus formas de personificación instrumental, para ofrecer todo tipo de servicios de calidad.

En términos generales, la autoprovisión posee la capacidad de potenciar un mercado público de bienes y servicios, distinto, y compatible, con el propio mercado privado.

Así, dentro de nuestra tradición jurídica más próxima, la francesa, desde la Decisión Bourrageas et Moullot de 26 junio de 1930 (N. 91176), la Decisión Société Unipain de 29 de abril 1970 (N. 77935), hasta la Decision Association pour la promotion de l'image de 26 de octubre de 2011 (N. 317827), se ha venido afirmando con claridad que una entidad pública es libre de satisfacer a través de sus propios servicios las necesidades públicas, y que, además, un servicio de una entidad pública puede ofrecer prestaciones a otro servicio de esa entidad. Un ayuntamiento puede proveerse de su propio papel y de su servicio de imprenta sin necesidad de externalizar el suministro o el servicio; una panadería militar puede vender pan a una prisión, del mismo modo que una banda militar puede ofrecer un concierto en un espectáculo organizado por el Ministerio de Cultura, sin necesidad de concurrencia.

Llevando la idea de la capacidad prestacional de las Administraciones hasta sus últimas consecuencias, el Consejo de Estado francés ha validado recientemente en su Decisión de 14 de junio de 2019 (N. 411444) la posibilidad de que un departamento francés (el de la Charente-Maritime) presentase oferta y ganase un concurso de servicios de dragado de un estuario licitado por un departamento vecino (el de la Vendée).

Con ello, paradójicamente, se abre el camino a que las necesidades públicas de una determinada administración se puedan satisfacer no con mecanismos de colaboración administrativa, sino aprovechando las ofertas competitivas (tanto en precio como en calidad) que, en el marco de los procedimientos de concurrencia competitiva contractual, puedan presentar otras administraciones, en la línea ya defendida por el propio Tribunal de Justicia(25). Más allá de la colaboración interadministrativa, tan característica del sector público, las administraciones tienen el potencial suficiente como para configurar empresas de titularidad y control públicos, prestadoras de servicios en régimen de mercado tanto para las propias administraciones como para el mercado general.

En estos nacientes mercados públicos, la oferta de autoprovisión administrativa crea un circuito de gastos e ingresos que refuerzan en términos macroeconómicos tanto la oferta como la demanda interna del sector público. Y, al desarrollarse en un entorno institucional ampliamente regulado por el Derecho público, la autoprovisión es susceptible de conseguir la realización de obras, suministros y servicios en unos estándares de producción más garantistas que los del mercado, en términos de estructura de costes, trazabilidad y transparencia, empleo de calidad, etc.

El abanico de efectos que todo ello puede generar va más allá de lo macroeconómico, adentrándose en la consecución de valores constitucionales (justicia y equidad social, solidaridad intergeneracional) que sólo una robusta economía social de mercado será capaz de garantizar.

Mediante la autoprovisión administrativa, en definitiva, es posible disponer de una herramienta real con la que fortalecer el (frágil) Estado de Bienestar español que tenemos la obligación de legar a las generaciones futuras.

(25) Véase Sentencia de 18 de diciembre de 2014, asunto C-568/13, Azienda Ospedaliero Universitaria di Careggi-Firenze, que admite dentro del concepto de "prestadora de servicios" de la Directiva 92/50 a un hospital universitario público que había realizado una oferta anormalmente baja para ganar un concurso de un contrato de servicios de tratamiento de datos para la evaluación externa de la calidad de los medicamentos. El Tribunal concluye que "las disposiciones de la Directiva 92/50, y en particular los principios generales de libre competencia, de no discriminación y de proporcionalidad en los que se basa esa Directiva, deben interpretarse en el sentido de que no se oponen a una normativa nacional que permite a un hospital público, como el demandante en el litigio principal, que participe en una licitación presentar, gracias a la financiación pública que recibe, una oferta a la que ningún competidor puede hacer frente. No obstante, en el examen del carácter anormalmente bajo de una oferta en virtud del artículo 37 de dicha Directiva, la entidad adjudicadora puede tomar en consideración, por lo que respecta a la facultad de rechazar dicha oferta, la existencia de una financiación pública en favor de tal centro". 